\title{
Application of Measurement While Drilling Technology to Predict Rock Mass Quality and Rock Support for Tunnelling
}

\author{
Jeroen van Eldert ${ }^{1}$ (D) Håkan Schunnesson ${ }^{1} \cdot$ Daniel Johansson $^{1}$ (D) $\cdot$ David Saiang $^{1}$ (D)
}

Received: 29 January 2019 / Accepted: 19 September 2019 / Published online: 9 October 2019

(c) The Author(s) 2019

\begin{abstract}
A tunnelling project is normally initiated with a site investigation to determine the in situ rock mass conditions and to generate the basis for the tunnel design and rock support. However, since site investigations often are based on limited information (surface mapping, geophysical profiles, few bore holes, etc.), the estimation of the rock mass conditions may contain inaccuracies, resulting in underestimating the required rock support. The study hypothesised that these inaccuracies could be reduced using Measurement While Drilling (MWD) technology to assist in the decision-making process. A case study of two tunnels in the Stockholm bypass found the rock mass quality was severely overestimated by the site investigation; more than $45 \%$ of the investigated sections had a lower rock mass quality than expected. MWD data were recorded in $25 \mathrm{~m}$ grout holes and $6 \mathrm{~m}$ blast holes. The MWD data were normalised so that the long grout holes with larger hole diameters and the shorter blast holes with smaller hole diameters gave similar results. With normalised MWD data, it was possible to mimic the tunnel contour mapping; results showed good correlation with mapped $Q$-value and installed rock support. MWD technology can improve the accuracy of forecasting the rock mass ahead of the face. It can bridge the information gap between the early, somewhat uncertain geotechnical site investigation and the geological mapping done after excavation to optimise rock support.
\end{abstract}

Keywords Measurement while drilling (MWD) $\cdot$ Rock mass investigation $\cdot$ Tunnelling $\cdot$ Rock mass quality $\cdot$ Rock support $\cdot$ Drill and blast technology

\section{Introduction}

Before a tunnelling project starts, a site investigation is performed to determine the in situ rock mass conditions. The information on the rock mass properties is then used to determine the excavation layout and the required type and volume of rock reinforcement (Barton et al. 1974; Lindfors et al. 2015). Site investigations use rock mass classification systems such as those introduced by Barton et al. (1974),

Jeroen van Eldert

jeroen.van.eldert@1tu.se

Håkan Schunnesson

hakan.schunnesson@1tu.se

Daniel Johansson

daniel.johansson@1tu.se

David Saiang

david.saiang@1tu.se

1 Division of Mining and Geotechnical Engineering, Luleå University of Technology, 97187 Luleå, Sweden
Bieniawski (1973) and Hoek and Brown (1997). However, since these systems often have limited availability of information (surface mapping, geophysical profiles, limited bore holes, etc.), the rock mass classification may be inaccurate, leading to increased excavation time and costs (Wahlström 1964; U.S. National Committee on Tunneling Technology 1984; Kjellström 2015).

Scandinavian hard rock tunnelling is most commonly performed by conventional drill and blast excavation. This method ensures flexibility in different tunnel cross sections and has the possibility to be adapted to changing rock mass conditions. The excavation cycle in water-bearing areas is proceeded by pre-grouting followed by blast-hole drilling, blasting, mucking and ground support installation. The excavation normally takes place in $\sim 5 \mathrm{~m}$ blast cycles. After mucking the blasted material, the tunnel perimeter is assessed for fractures and estimation rock mass quality using rock mass classification system such as rock mass rating (RMR) and the Q-system. The as-designed support systems are validated against the observations or in some cases the 
support systems are revised to suit the rock mass conditions. The rock mass classification and rock support installation are also normally performed in $\sim 5 \mathrm{~m}$ sections. Therefore, smaller areas of poorer or better rock conditions may be difficult to include. Therefore, these systems may over- or underestimate the true rock mass conditions and the required rock support (Edelbro 2004).

To minimise these problems, a more thorough and detailed pre-investigation could be an alternative, but reaching significantly higher accuracy is expensive. Another alternative could be to use information extracted during construction, but this requires shorter planning horizons and a more flexible organisation.

A more precise and objective method for rock mass characterisation and ultimately rock support design is measurement while drilling (MWD). The MWD technology documents the response of the drilling parameters (e.g. penetration rate, operational pressures, rotation speed, flushing flow, etc.), while drilling (Schunnesson 1996). It has been demonstrated to be an objective and reliable method to assess rock mass conditions ahead of the tunnel face (Schunnesson 1996, 1998; Atlas Copco Rock Drills AB 2009; Schunnesson et al. 2011; Humstad et al. 2012; Van Eldert et al. 2017). This method was employed by Schunnesson (1996) to study the drilling responses to fractured rock mass. According to Barr (1984), drilling parameters show signature behaviour when intersecting an open fracture, including: (1) a short-lived but significant increase of the penetration rate, (2) a minor and temporary decrease in the rotation pressure, (3) a drop in water pressure and (4) large fractures show a temporary reduction in feed pressure. The predominant parameter for fracture indication, the penetration rate, was employed by Scoble and Peck (1987) to asses fractures observed with borehole TV and in core drilling. In their study, the behaviour of the penetration rate corresponded very well to the fractures in the rock mass detected with borehole TV and in drill core. Schunnesson (1990) employed MWD technology for percussive drilling at the
Kirunavaara mine. Schunnesson's (1990) study showed that rotation pressure was increased in a fracture zone, where the penetration rate was decreased. The penetration rate showed a significant variation while passing through the fracture zone. A similar variation was observed at field tests in Zinkgruvan (Schunnesson 1998) where the penetration rate generally increased while showing large variations. These examples show that both the penetration rate and the rotation pressure are strongly affected by the degree of fracturing in the rock mass. The increased magnitude and variation of the penetration rate and rotation pressure are associated with the degree of fracturing, which may correlate to Rock Quality Designation or RQD. The relative variation of the penetration rate and rotation pressure is employed to establish the Fracture Index in Epiroc's Underground Manager and in independent research (Ghosh 2017).

This paper investigates the quality and usability of MWD data in tunnelling and suggests an approach to incorporate the use of MWD technology into the rock support design process in the production phase of a tunnelling project to improve time and cost efficiency.

The paper is based on a case study from the large Swedish infrastructure project, the Stockholm bypass, a tunnel excavation in competent Scandinavian hard rock.

\section{Case Study Description}

The Stockholm bypass is being constructed to improve transport links within the Stockholm metropolitan region. The bypass consists of a new $21 \mathrm{~km}$ road, of which $18 \mathrm{~km}$ will be underground (Trafikverket 2018).

This study focusses on the first section of two access tunnels to the underground portion of the Stockholm bypass at the Skärholmen area namely Tunnel 213 and Tunnel 214; see Fig. 1. A separate site investigation was performed by Arghe $(2013,2016)$. The investigation included four diamond core holes (0-120 $\mathrm{m}$ from the tunnels), two seismic lines, and the

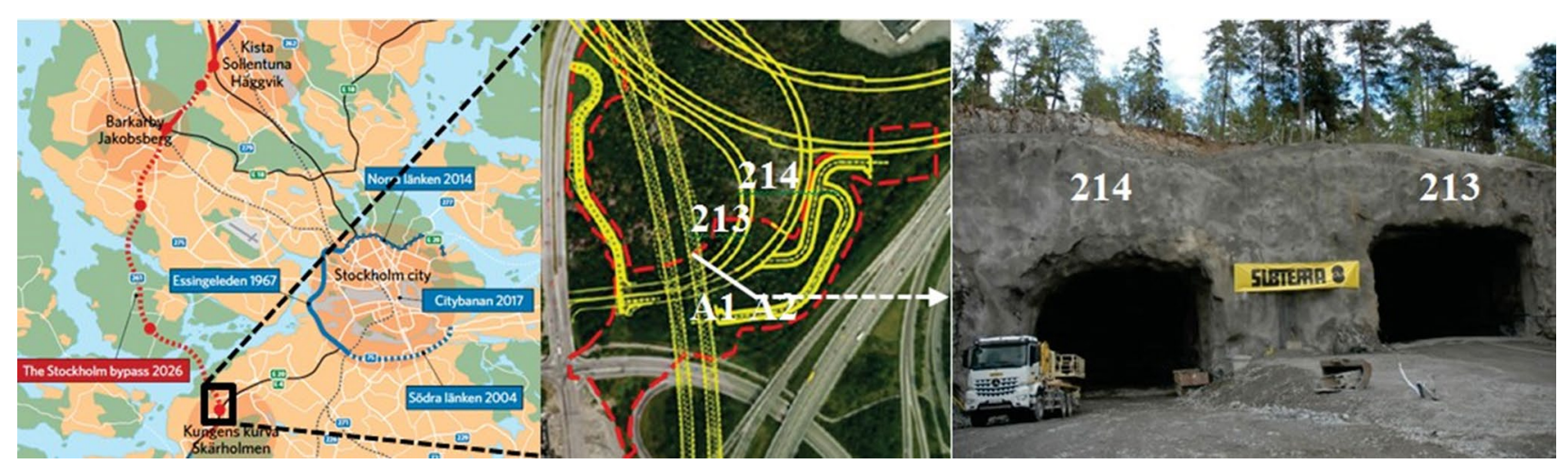

Fig. 1 Tunnel 213 and Tunnel 214 in Stockholm bypass (Illustrations courtesy of Trafikverket) 
mapping of a nearby subway tunnel. The reports describe the rock mass as grey, medium- to large-grained gneiss with intrusions of lightly foliated granite, pegmatite, greenstone, graphite amphibolite, and severely weathered mica. They also identify four zones of weakness (Arghe 2013, 2016).

\section{Methodology}

The results presented in this paper are based on the data collected before and during the tunnel construction of the two access tunnels displayed in Fig. 1.

A number of rock mass classification systems have been developed over the years; of these, rock mass rating (RMR) (Bieniawski 1973) and tunnelling quality index or the Q-system (Barton et al. 1974) are the most commonly used. The Q-system is a tunnelling data-based empirical classification system that categorises the ground into nine rock mass classes and is used to estimate rock support. The Q-system was initially developed for Scandinavian hard rock excavations and is, therefore, still widely used in Scandinavia. The quality index ranges from 0.001 to 1000 and is calculated using Eq. 1.

$Q=\frac{\mathrm{RQD}}{J_{\mathrm{n}}} \times \frac{J_{\mathrm{r}}}{J_{\mathrm{a}}} \times \frac{J_{\mathrm{w}}}{\mathrm{SRF}}$

where RQD is the rock quality designation, $J_{\mathrm{n}}$ is the joint set number, $J_{\mathrm{r}}$ is the joint roughness number, $J_{\mathrm{a}}$ is the joint alteration number, $J_{\mathrm{w}}$ is the joint water number, and SRF is the stress reduction factor.

The rock mass conditions along Tunnels 213 and 214 were established by $Q$-values in two phases: (1) "initial $Q$-values" from the site investigation prior to construction were used to establish the ground support requirements (Arghe 2013, 2016); (2) "mapped $Q$-values" from the tunnel mapping during construction ( $\mathrm{\AA F}$ unpublished data, 2016) were the basis for the installed rock support.

Drilling for the tunnel construction was performed by an Atlas Copco WE3 3-Boom drill rig using three COP3038 hydraulic percussive rock drills. The rig was equipped with a fully integrated MWD system that recorded penetration rate, percussive pressure, feed pressure, rotation pressure, rotation speed, damping pressure, flushing flow, and pressure at defined intervals along the hole. For this test, the sampling interval was set at $2 \mathrm{~cm}$, but because of the high penetration rate (Atlas Copco Rock Drills AB 2009), the actual sample interval was between $2 \mathrm{~cm}$ and $3 \mathrm{~cm}$. The MWD data were applied to calculate drilling indices: Hardness Index (HI) and Fracture Index (FI). In Atlas Copco's Underground Manager MWD V1.6 (UM), the FI is calculated based on the variation from the normalised penetration rate and normalised rotation pressure (Schunnesson 1990). Thus, the FI displays the variation of drilling parameters while drilling. The variation in the calculated Fracture Index reflects the heterogeneity of the rock mass (Schunnesson 1996, 1998; Van Eldert et al. 2016). This heterogeneity is correlated to the degree of fracturing of in Scandinavian hard rock masses (Schunnesson 1996). For the calculation of FI in UM, penetration rate, feed pressure, percussive pressure, and rotation pressure are all corrected for the effects of the drill hole length. In addition, the penetration rate and rotation pressure are corrected for the regression of the percussive pressure. These two parameters are scaled, followed by a summation of the normalised residuals of the penetration rate and the rotation pressure.

During the tunnel excavation, MWD data were collected for grout holes drilled in fans ahead of the face and for blast holes. In Tunnel 213, the first $90 \mathrm{~m}$ was monitored; in Tunnel 214, the first $220 \mathrm{~m}$ was monitored. Altogether, MWD data were gathered from 579 grout holes (18 rounds) and 8 511 blast holes (43 rounds), as displayed in Table 1.

The MWD data are collected continuously during the drilling process. These machine data normally contain some faulty, biased or unrealistic data (Van Eldert et al. 2017), due to the nature of the drilling process, sensor errors or machine safety systems (anti-jamming). These erroneous data points must be removed before analysis can be done to assess the rock mass condition. Some data points can easily be defined as incorrect, such as negative rotation speeds (reverse drilling), very high penetration rates (over $48 \mathrm{~m} / \mathrm{min}$ ), or 0 -values among the parameters. The data set will also have data that are correct but not common and there will be a sliding transition from faulty data to abnormal drilling behaviour. This causes a problem when filtering data. Fortunately, for this type of high resolution of data set, more extensive filtering can be done without losing the general pattern of the data. The data quantity minimise the effect of removal of correct but abnormal data points.

In this case study, a conservative statistical approach was used to remove the highest and lowest values. The rounded filter limits in Table 2 were set at minimal three times the standard deviations away from the mean; the values outside these filter limits were removed. Ultimately, more than $99.7 \%$ of the data points were accepted, with $0.14 \%$ removed at the low end and $0.14 \%$ removed at the high end. If one or more of the recorded parameters fell outside the interval,

Table 1 Round and holes investigated

\begin{tabular}{lccclll}
\hline Tunnel & $\begin{array}{l}\text { Tunnel length } \\
\text { investigated }(\mathrm{m})\end{array}$ & \multicolumn{2}{l}{ Number of rounds } & \multicolumn{2}{l}{$\begin{array}{l}\text { Number of } \\
\text { holes }\end{array}$} \\
\cline { 3 - 4 } \cline { 6 - 7 } & & Grout & Blast & & Grout & Blast \\
\hline 213 & 90 & 7 & 17 & & 240 & 3809 \\
214 & 220 & 11 & 26 & & 339 & 4702 \\
\hline
\end{tabular}


Table 2 Filter limits for MWD parameters

\begin{tabular}{lll}
\hline Recorded parameters & $\begin{array}{l}\text { Ranges of } \\
\text { recorded raw } \\
\text { data }\end{array}$ & Selected filter limit \\
\hline Penetration rate (m/min) & 0 and 48.8 & $\geq 0$ and $\leq 7.5$ \\
Percussive pressure (bar) & 0 and 215 & $\geq 90$ and $\leq 200$ \\
Feed pressure (bar) & 0.42 and 192 & $\geq 20$ and $\leq 90$ \\
Rotation pressure (bar) & 1,28 and 162 & $\geq 35$ and $\leq 100$ \\
Rotation speed (RPM) & -196 and 374 & $\geq 200$ and $\leq 340$ \\
Damper pressure (bar) & 9.75 and 176 & $\geq 35$ and $\leq 95$ \\
Flushing water pressure (bar) & 0 and 122 & $\geq 2$ and $\leq 35$ \\
Flushing water flow (1/min) & 0 to 261 & $\geq 60$ and $\leq 210$ \\
\hline
\end{tabular}

the entire sample was rejected. The filtering limit used by the study is shown in Table 2. The Hardness Index and Fracture Index were calculated using the Underground Manager software for filtered and normalised samples (Schunnesson 1996, 1998; Van Eldert et al. 2017).

The monitored MWD data showed significant differences in the values for the grout and blast holes. The recorded MWD values generally vary significantly with hole diameter and hole length. Penetration rate, for example, is higher for smaller holes and lower for larger ones. Penetration rate always decreases with increasing hole length. In this case, MWD data from two types of holes were available: blast holes with $48 \mathrm{~mm}$ diameter and $5.7 \mathrm{~m}$ length and grout holes with $64 \mathrm{~mm}$ diameter and 20-25 m length. The blast holes are all located within the tunnel perimeter, where the grout holes have the hole ends up to $5 \mathrm{~m}$ outside the tunnel perimeter.

To compare the MWD response for the blast holes and grout holes, the data response must be normalised. The initial normalisation procedure used in this case follows Ghosh (2017):

1. Calculate the average or median (for symmetrically distributed data) or mode (for unsymmetrically distributed data) (Mo) and standard deviation $(\sigma)$ of the selected parameter.

2. Normalise the residual of each data point using the standard deviation of the data, Eq. 2.

Normalise data $=\frac{\text { values }- \text { Mo }}{\sigma}$

Figure 2 shows the normalisation of the Fracture Index for the grout holes and blast holes. The Fracture Index was normalised using the standard deviation. The Residual
Fig. 2 Normalisation of the Fracture Index of the grout and blast holes; a raw data and $\mathbf{b}$ normalised data
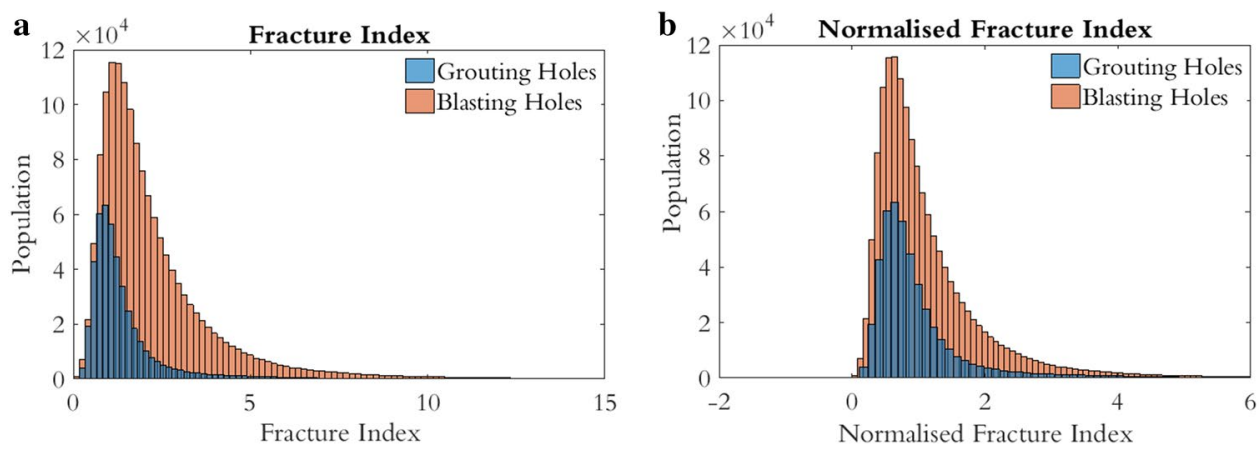
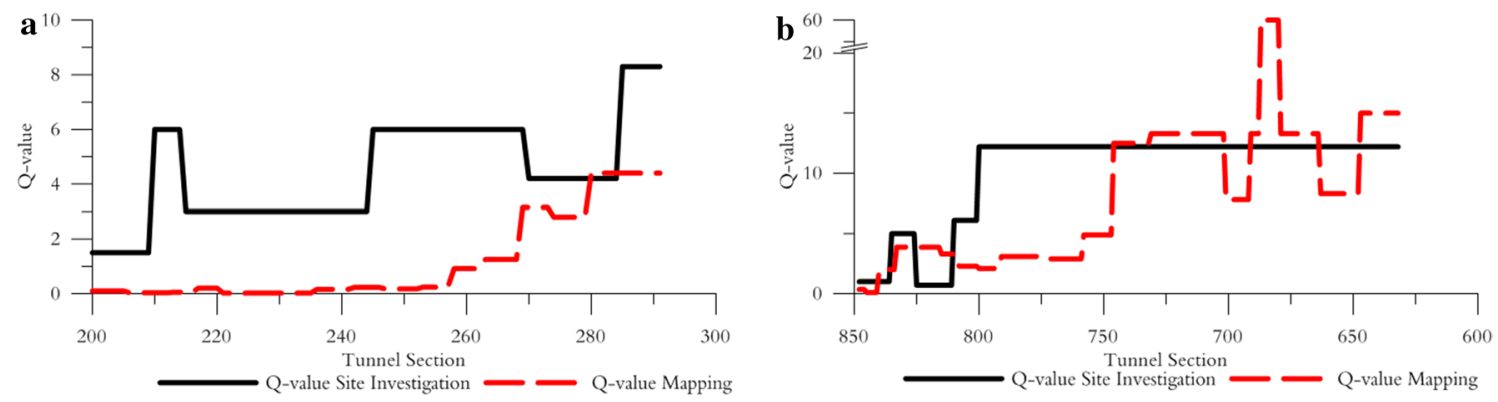

Fig. $3 Q$-values established during site investigation (Arghe 2013, 2016) and from tunnel mapping (ÅF, unpublished data, 2016) for Tunnel 213 (a) and Tunnel 214 (b) 
Index was not calculated, as the data set has a very similar response.

\section{Results}

The rock mass characterisation described by the $Q$-values was defined by the site investigation before excavation started and by tunnel mapping during construction. These data sets are compared in Fig. 3a for the first $90 \mathrm{~m}$ of Tunnel 213 and in Fig. $3 b$ for the first $220 \mathrm{~m}$ of Tunnel 214.

As the figure shows, in Tunnel 213, the first $80 \mathrm{~m}$ of the tunnel had a significant lower mapped $Q$-value than estimated in the site investigation, indicating that the real rock conditions initially were much poorer than expected. In most of the section (63\%), the mapped $Q$-value was 10 times lower than estimated. The conditions in Tunnel 214 followed a similar pattern, in that the first $100 \mathrm{~m}$ had a very low $Q$-value. In this case, however, the site investigation indicated low values for the first $50 \mathrm{~m}$, so the estimation was reasonably accurate. But there was a big mismatch between the estimated and mapped $Q$-values for the following $50 \mathrm{~m}$. Furthermore, several fracture zones at the tunnel entrances were not noticed during the site investigation.

As a consequence of the large difference between the $Q$-value estimated by the site investigation and the mapped $Q$-value, the rock mass support was increased during construction. Figure 4 compares the estimated bolt spacing, bolt length and sprayed concrete thickness, based on the site investigation, with the installed rock support during construction.

Because the rock conditions were worse than estimated by the site investigation, the bolt spacing was decreased from selective bolting to $1.7-1.3 \mathrm{~m}$ in the major parts of both tunnels (Fig. 4a).

The bolt length was increased from 3 to $6 \mathrm{~m}$ in the least favourable parts of the tunnel, especially in Tunnel 213 (Fig. 4b). These increases of bolt length were unexpected and not conform to the Q-system. In the Q-system, the bolt length is not dictated by the rock mass quality but the span or height of the opening divided by the Excavation Support Ratio (ESR) (Barton et al. 1974). In this case, the extended bolt length was caused due to up to $4.5 \mathrm{~m}$ zones with alternating graphite and clay bands. In between these zones, the rock mass was observed to be consisting of small blocks and to be oxidised ( $\AA F$ 2016). These graphite and clay-rich deformation zones were deemed unsuitable for the anchorage of rock bolts. To overcome this safety risk, longer $6 \mathrm{~m}$ bolts were selected to secure proper rock bolt anchorage and thus fix the sprayed concrete layer to the competent rock mass. Therefore, the increased bolt length is correlated to the rock mass quality in this case study.
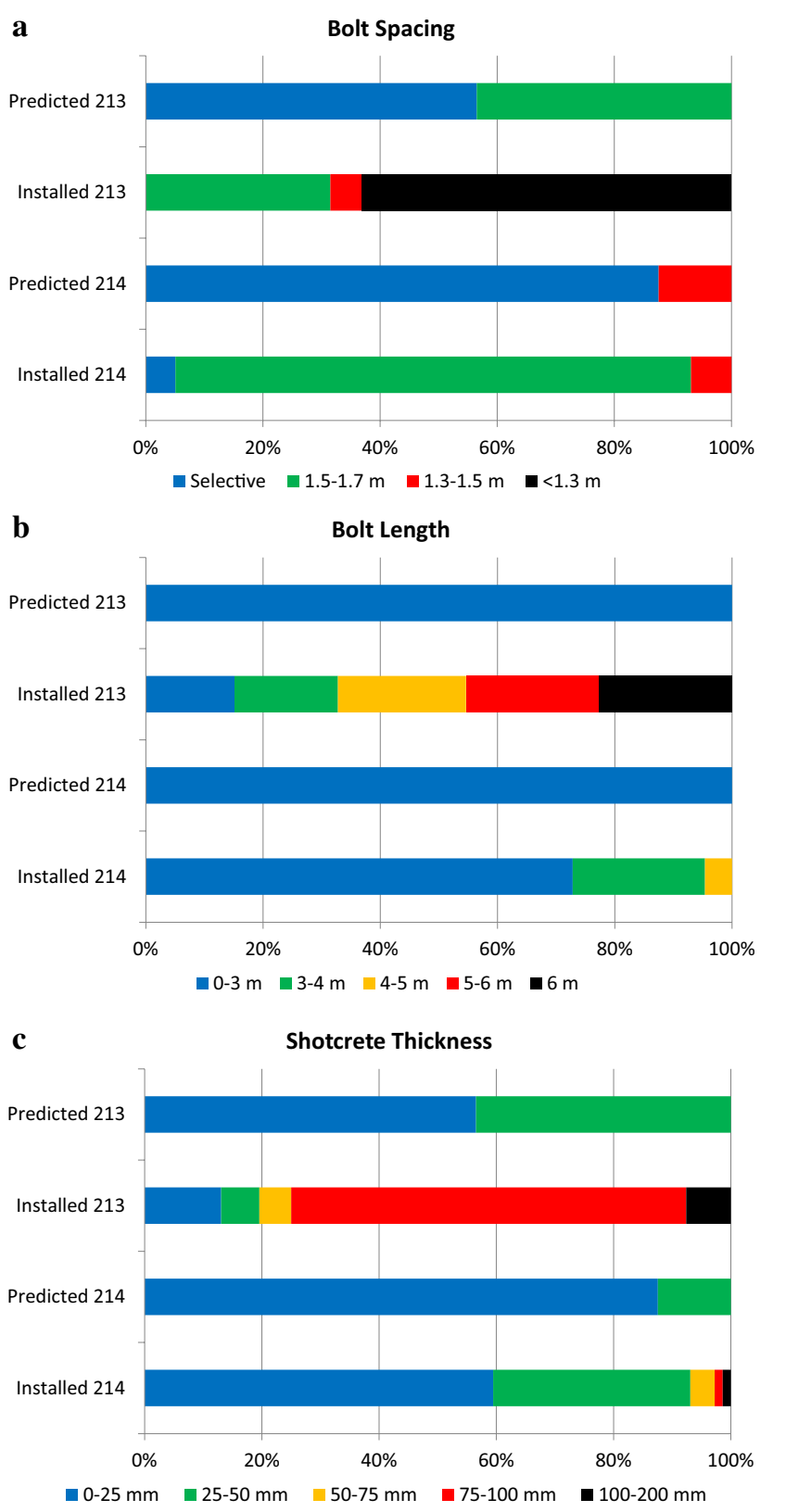

Fig. 4 Predicted and installed bolt spacing (a), bolt length (b) and sprayed concrete thickness (c) in Tunnel 213 and Tunnel 214. Length is defined as the percentage of tunnel section, i.e. $90 \mathrm{~m}$ for Tunnel 213 and $220 \mathrm{~m}$ for Tunnel 214

An additional amount of sprayed concrete was installed in both tunnels. In Tunnel 213, the sprayed concrete thickness increased significantly from the amount estimated by the site investigation (Fig. 4c); overall, more than twice the amount of sprayed concrete was required. The effects of the graphite-clay zones required the installation of $200 \mathrm{~mm}$ thick sprayed concrete arches at the tunnel entrances. In addition, over-break occurred in the tunnel sections with the graphite-clay zones. 
The use of MWD may be able to minimise the consequences of the knowledge gap between the initial site investigation and the experienced rock mass conditions during excavation. It may increase the knowledge of the rock mass conditions and improve the accuracy of the rock characterisation ahead of the face. In the test site, MWD was used for both the blast holes and the grout holes in both ramp tunnels. Figures 5 and 6 compare the geotechnical mapping of the tunnels with the interpolated Fracture Index based on MWD data. In Tunnel 213, the Fracture Index shows highly fractured areas at the tunnel portal (i.e. section 200 to section 265) in section 230 to 232 and in section 238 to 260; this corresponds well with the geotechnical mapping of the tunnel. The fracture zones cross the tunnel at a $30^{\circ}$ angle to the tunnel centre line. The location and the orientation of these areas are shown by the black lines in Fig. 5. In Tunnel 214 , fracture zones are observed at the tunnel portal (the first $10 \mathrm{~m}$ ) and in section 850 to 835 in the MWD data for the grout holes and the blast holes and in the geotechnical mapping. The location and the orientation of these areas are denoted by the black lines in Fig. 6. In both cases, the mapped rock mass characterisations are better portrayed by the blast hole MWD data. This is caused by the geometry of the drilling fans, where the grout holes are located up to 5 $\mathrm{m}$ from the tunnel perimeter and the blast holes are located at the tunnel perimeter.

The calculated Fracture Index is based on the drill rig response when penetrating the fractured rock mass. It is independently recorded and is measured at high resolution along every hole. This high-resolution data set facilitates identification of smaller zones in the tunnel and rock mass characteristics for the remaining rock mass (up to $5 \mathrm{~m}$ from the rock surface), as the grout holes are inclined.

The $Q$-value is based on six parameters (see Eq. 1); it is often estimated for entire tunnel sections, such as $5 \mathrm{~m}$ blasts. Each parameter must be manually estimated. As the estimation of parameters requires skills and experience, the $Q$-value will be biased and influenced by personal differences (Edelbro 2004). Therefore, even if the $Q$-value theoretically includes a better and wider description of the rock mass, it is highly dependent on the person performing the mapping and is limited to visible parts of the tunnel. In contrast, MWD only records fracturing of the rock mass with very high resolution, including the rock mass outside the tunnel contour.

To test how well the Fracture Index correlates with the $Q$-value in the case study, the mapped $Q$-values were
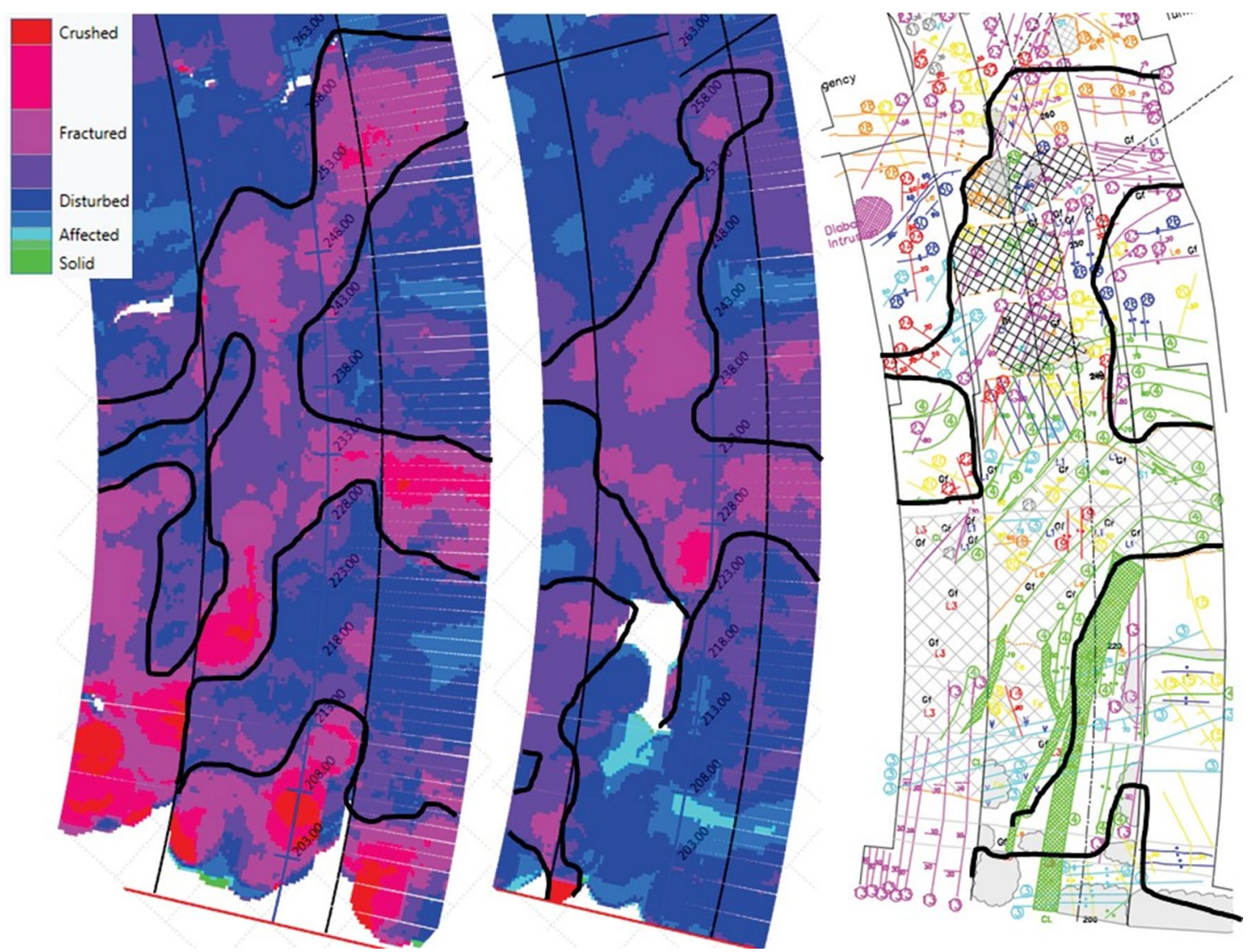

Fig. 5 Fracture Index from MWD data and geotechnical mapping for Sections 200 to 263 in Tunnel 213 calculated in Underground Manager (left to right grout holes, blast holes, geotechnical mapping) 

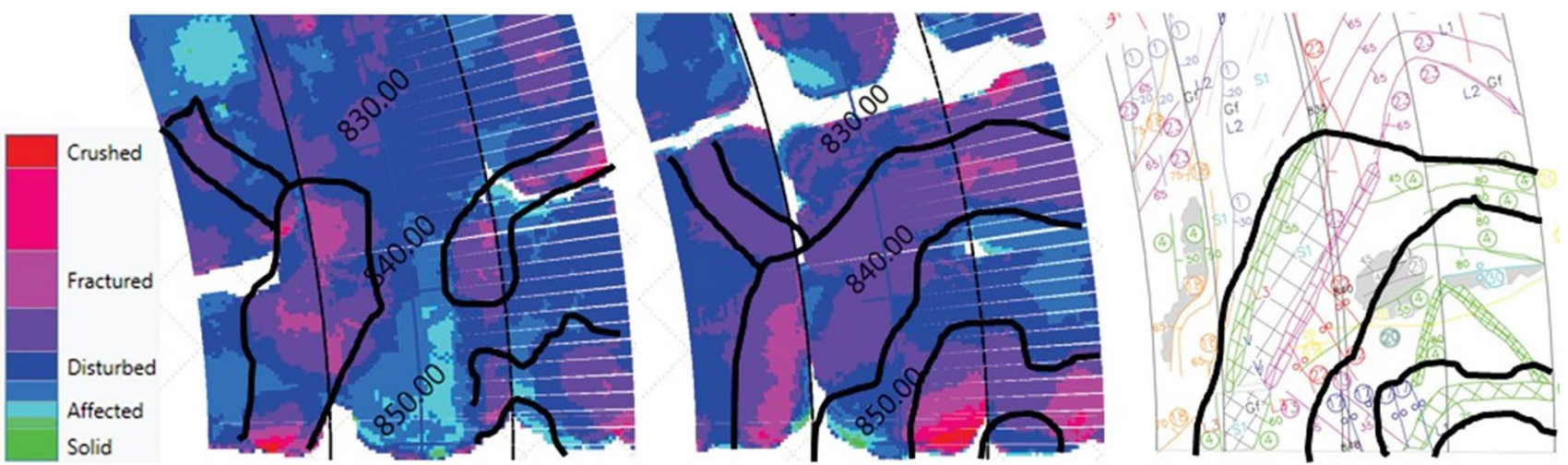

Fig. 6 Fracture Index from MWD data and geotechnical mapping for Sections 850 to 820 in Tunnel 214 calculated in Underground Manager ${ }^{\mathrm{TM}}$ (left to right grout holes, blast holes, geotechnical mapping)

compared with the calculated Fracture Index from 24 different locations in both tunnels; see Fig. 7.

The figure shows a clear negative correlation between the $Q$-value and the Fracture Index, where more fractured rock corresponds to a lower $Q$-value. In a construction like this, the $Q$-value is basically used to estimate required rock support, and with the correlation presented in Fig. 7, it may be possible to use MWD.

The rock mass conditions along the tunnel paths varied considerably (see Fig. 3), resulting in a large variation in installed rock support. The support options for the tunnels include bolts with different lengths (from no bolts to $6 \mathrm{~m}$ bolts), different bolt spacing (from selective bolting to $0.8 \mathrm{~m}$ spacing) and different sprayed concrete thickness (from no sprayed concrete to $200 \mathrm{~mm}$ thickness).

Figure 8 shows the correlation between MWD fracturing response and the installed rock support for 24 locations along the tunnels. The figure shows that a favourable rock mass, low Fracture Index, requires less rock support. A poor rock mass, high Fracture Index, requires more rock support.

In general, the bolt spacing decreases and bolt length and sprayed concrete thickness increase in "poorer rock" with a higher Fracture Index. For a Fracture Index from 2 to 5, the installed rock supports are quite consistent for bolt length, bolt spacing, and sprayed concrete thickness. For a low Fracture Index, i.e. below 2, indicating a more solid rock mass, the variation is much larger. Some sections have shorter bolts, larger bolt spacing, and thinner sprayed concrete layer, and this is logical. However, other sections are similar to those with a high Fracture Index; some even have a thicker sprayed concrete layer and reduced bolt spacing. In addition, Fig. 8 shows several sections with a low Fracture Index and relative thick sprayed concrete layer and tight bolt spacing. This phenomenon suggests that the rock mass in some sections may be over-supported; these sections are marked with the dashed circle in Fig. 8. Figure 8c displays one section where the rock mass may be under-supported, being a potential risk. Figure $8 \mathrm{a}$, c shows a clear trend of the correlation between the rock support and the MWD Fracture Index, as shown with the lines in Fig. 8.

\section{Discussion and Conclusions}

The results from the study show the potential for the use of MWD to predict rock mass conditions ahead of the face. Figures 5 and 6 show a clear correspondence between the MWD findings and manually mapped rock conditions. There is also a correlation between the Fracture Index, based on MWD, and the mapped $Q$-index.

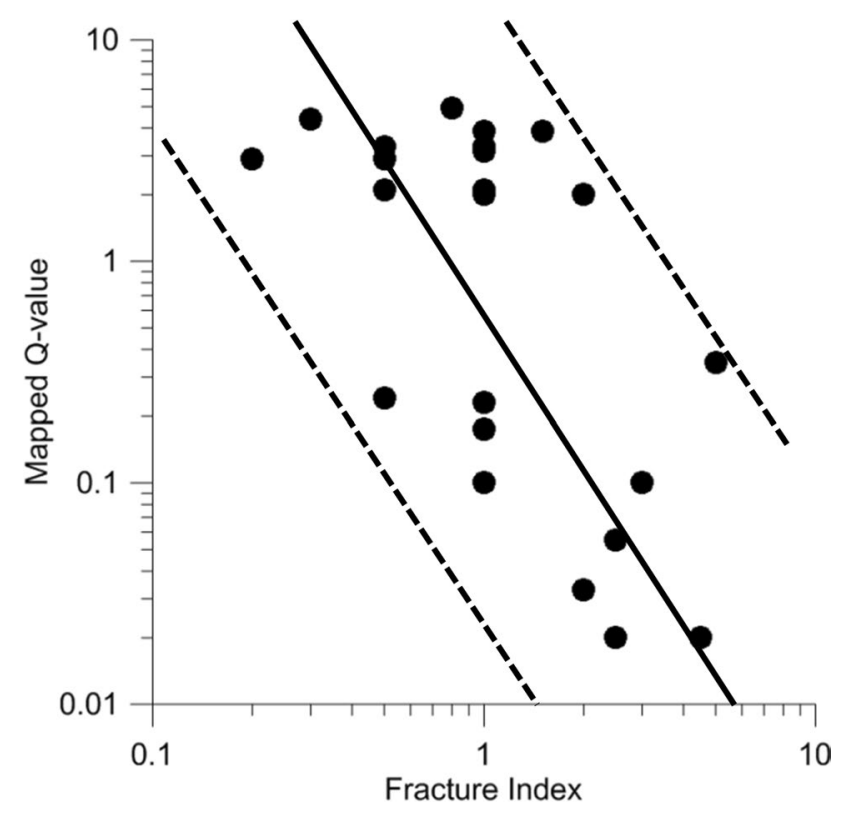

Fig. 7 Relations between mapped $Q$-values and MWD Fracture Index on a log-log scale 
The installed rock support correlates to the Fracture Index, except for low fracture index values (solid rock), where there is a large variation in applied rock support. There may be several reasons for this, but a discrepancy between the rock condition predicted by the site's pre-investigation and the rock condition experienced during excavation may result in more installed support than is actually required.

The traditional procedure for infrastructure projects based on pre-investigation and mapping during excavation may benefit from additional on-line rock mass information, even if the information comes at a late stage in the planning process. The MWD data are independently recorded, have high
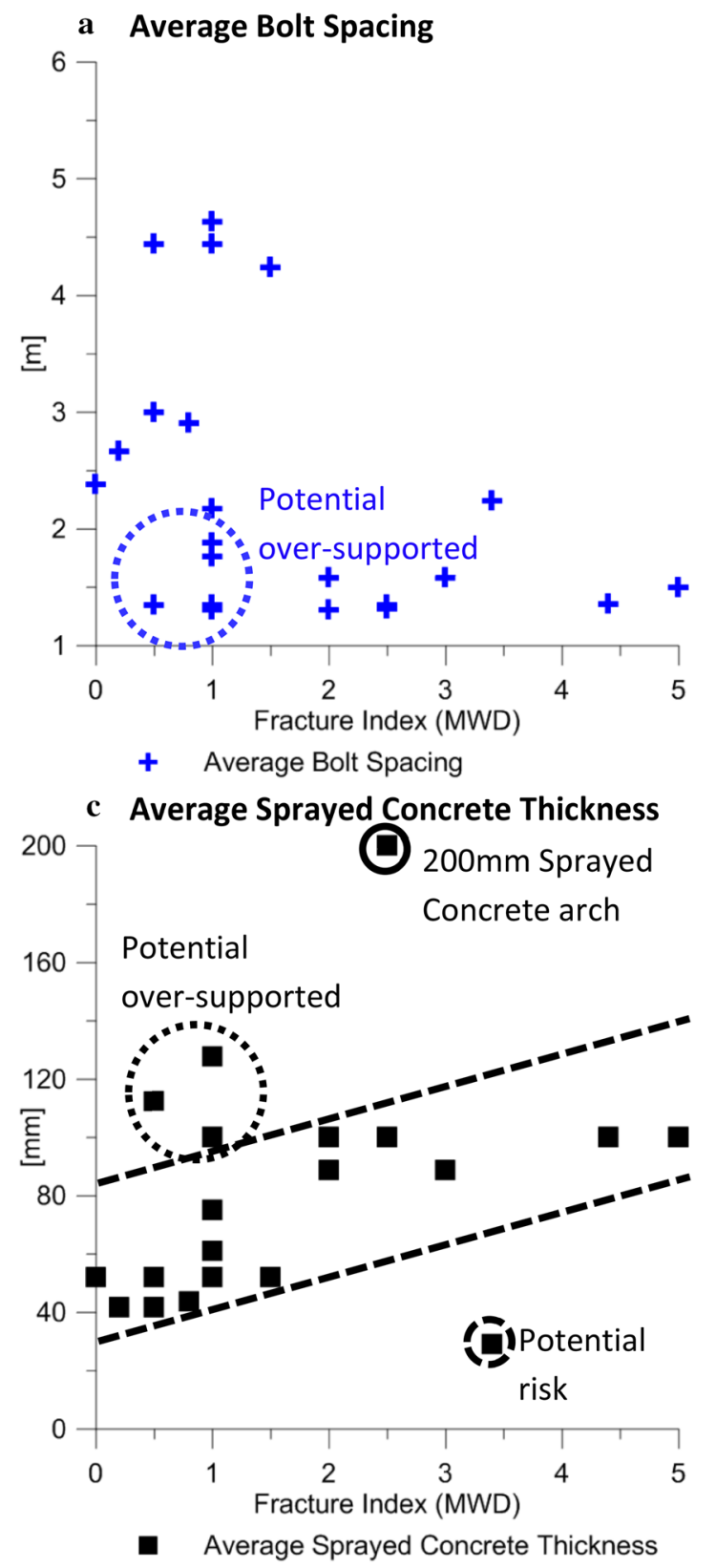

resolution and include information on the rock mass outside the tunnel profile.

To test the accuracy of MWD technology, the MWD data for short blast holes and long grout holes were normalised and analysed. For the blast holes, the time interval between drilling and support installation is often very short, and the time available to make decisions on changes or modifications in the required support may be inadequate. However, the grout holes are drilled 20-25 m ahead of the face, and the time interval before the face catches up can be a week or longer. This time interval may be long enough to re-characterise the rock mass and adjust the preliminary rock support design based on the

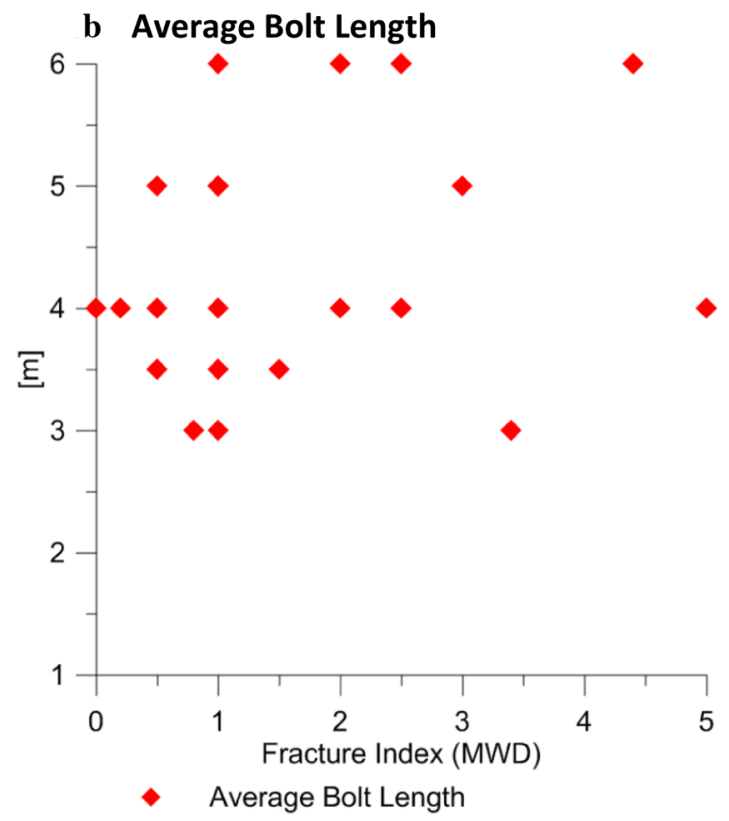

Fig. 8 Correlations between MWD Fracture Index and installed rock support in 24 sections of $1 \mathrm{~m}$ along the two tunnels 
seen rock characteristics. The following blast hole drilling can then be used to verify the expected rock mass conditions.

This procedure can reduce risk and may provide the opportunity to prepare the excavation work for unexpected rock mass conditions, hence reducing delays. The use of MWD data in the rock support design may also result in a more efficient workflow, as these data cover the information gap between the somewhat uncertain geotechnical site investigation and the post-excavation geological mapping.

The specific conclusions from this study are the following:

- The $Q$-value determined from the initial site investigation was inaccurate and significantly overestimated the rock mass conditions.

- The MWD data from grout and blast hole can be normalised to overcome differences in geometry of the drill holes, bit size, and hole length to provide identical rock mass characterisation.

- The Fracture Index shows good correlation to the mapped $Q$-value, suggesting its potential as an additional information source for rock support requirements.

- The use of MWD technology can bridge the information gap between the early, somewhat uncertain geotechnical site investigation and the geological mapping done after excavation to optimise rock support, to overcome shortcomings of the empirical observation-based methods.

Acknowledgements Open access funding provided by Lulea University of Technology. The authors wish to thank Subterra Sweden for providing all MWD data used in this study. Trafikverket (Swedish Traffic Authority) and $\AA F$ Sweden are acknowledged for the geological site investigation reports and structural mapping data for the tunnels. Finally, for funding BeFo (Stiftelsen Bergteknisk Forskning, Rock Engineering Research Foundation) and Swebrec (Swedish Blasting Research Centre) are acknowledged for providing financial support for BeFo project 344.

\section{Compliance with Ethical Standards}

Conflict of interest The authors declare that they have no conflict of interest.

Open Access This article is distributed under the terms of the Creative Commons Attribution 4.0 International License (http://creativeco mmons.org/licenses/by/4.0/), which permits unrestricted use, distribution, and reproduction in any medium, provided you give appropriate credit to the original author(s) and the source, provide a link to the Creative Commons license, and indicate if changes were made.

\section{References}

ÅF (2016) Project E4 Förbifart Stockholm, Förstärkningsanvisning. Unpublished data
Arghe F (2013) E4 Förbifart Stockholm FSE210 ArbetstunnelSkärholmen-Ingenjörsgeologisk prognos 13.4 BygghandlingArbetshandling 2013-08-30 2B141001.doc [E4 Stockholm bypass FSE210 access tunnels-Skärholmen-Engineering geological prognose 13.5-Construction document .... . Technical report (in Swedish)

Arghe F (2016) E4 Förbifart Stockholm FSE209 Bergtunnlar-Skärholmen-Ingenjörsgeologisk prognos-Bergteknik Handling 13.5Bygghandling 2015-03-04 (Rev B 2016-03-17) 2B141102-FSE209 [E4 Stockholm bypass FSE209 rock tunnels-Skärholmen-Engineering geological prognose-rock technical document 13.5Construction document ....]." Technical report (in Swedish)

Atlas Copco Rock Drills AB (2009) Atlas Copco Face drilling options Measurement While Drilling Technical specification. 98512456 01 a $02 / 2009$

Barr MV (1984) Instrumented horizontal drilling for tunnelling site investigations. Ph.D. Thesis, Imperial College of Science and Technology, London

Barton N, Lien R, Lunde J (1974) Engineering classification of rock masses for design of tunnel support. Rock Mech 6(4):189-236

Bieniawski ZT (1973) Engineering classification of jointed rock masses. Civil Eng S Afr 15(12)

Edelbro C (2004) Evaluation of rock mass strength criteria. Licentiate Dissertation, Luleå University of Technology

Ghosh R (2017) Assessment of rock mass quality and its effects on chargeability using drill monitoring technique. Dissertation, Luleå University of Technology

Hoek E, Brown ET (1997) Practical estimates of rock mass strength. Int J Rock Mech Min Sci 34(8):1165-1186

Humstad T, Høien AH, Kveen A, Hoel JE (2012) Complete software overview of rock mass and support in Norwegian road tunnels. Proc. Eurorock 2012, BeFo-Swedish Rock Engineering Foundation and the ISRM NG SWEDEN, Stockholm, Sweden

Kjellström I (2015) Utvärdering av skillnader vid karaktärisering och klassificering av bergkvalitet En jämförelse mellan förundersökning, prognos och byggskede i projekt Citybanan [Evaluation of differences with characterization and classification of rock mass quality A comparison between site investigation, prognosis and construction in the Citybanan project]. M.Sc. Thesis, Royal Institute of Technology, Stockholm, Sweden (in Swedish)

Lindfors U, Swindell R, Rosengren L, Holmberg M, Sjöberg J (2015) Projektering av bergkonstruktioner [Projection of rock constructions]. Trafikverket, Publication number: 2014:144, ISBN: 97891-7467-671-6 (in Swedish)

Schunnesson H (1990) Drill process monitoring in percussive drilling-a multivariate approach to data analysis. Licentiate thesis 1990:08L, Luleå University of Technology, Sweden

Schunnesson H (1996) RQD predictions based on drill performance parameters. Tunn Undergr Sp Tech 11(3):345-351

Schunnesson H (1998) Rock characterisation using percussive drilling. Int J Rock Mech Min Sci 35(6):711-725

Schunnesson H, Elsrud R, Rai P (2011) Drill monitoring for ground characterization in tunnelling operations. In: Proc. 20th international symposium on mine planning and equipment selection. National Center on Complex Procession of Mineral Raw Materials of the Republic of Kazakhstan, Almaty, Kazakhstan

Scoble MJ, Peck J (1987) A technique for ground characterization using automated production drill monitoring. Int J Surf Min 1:41-54

U.S. National Committee on Tunneling Technology (1984) Geotechnical site investigations for underground Projects. National Research Council, Washington, D.C., USA

Trafikverket (2018) E4 The Stockholm bypass Project. https://www. trafikverket.se/en/startpage/projects/Road-construction-projects/ the-stockholm-bypass/. Accessed 7 Jan 2019 
Van Eldert J, Ittner H, Schunnesson H, Johannsson D (2016) Evaluation of alternative techniques for excavation damage characterization. In: Proc., World Tunnelling Congress 2016. UCA of SME, San Francisco, California, United States of America

Van Eldert J, Schunnesson H, Johansson D (2017) The history and future of rock mass characterisation by drilling in driftingFrom sledgehammer to PC-tablet. In: Proc. 26th international symposium on mine planning and equipment selection. Luleå University of Technology, Luleå, Sweden

Wahlström EE (1964) The validity of geological projection a case history. Econ Geol 59:465-474

Publisher's Note Springer Nature remains neutral with regard to jurisdictional claims in published maps and institutional affiliations. 